\title{
LAS RELACIONES GEOGRÁFICAS Y EL CONOCIMIENTO DEL TERRITORIO EN TIEMPOS DE FELIPE II
}

\author{
POR \\ FERNANDO ARROYO ILERA
}

Las conocidas Relaciones Topográficas de Felipe II, uno de los documentos geográficos más significativos de ese reinado, han sido estudiadas en numerosas ocasiones y utilizadas para diversos tipos de trabajos e investigaciones. Como es sabido, se trata de las respuestas dadas a unos cuestionarios previamente preparados al efecto, realizadas en numerosas poblaciones americanas y peninsulares. En unos casos eran un repertorio de cuestiones que debían ser tenidas en cuenta por exploradores y oficiales reales y en otros se requería a los vecinos conocedores del lugar para que aportaran información sobre las características del territorio, producciones, economía, situación social, antecedentes históricos, costumbres, etc., pretendiendo así un registro de información geográfica que luego pudiera ser utilizada para diversos fines. Las Relaciones peninsulares constituyen ocho gruesos volúmenes que se conservan en la Biblioteca del Real Monasterio de San Lorenzo del Escorial, con información de unos setecientos pueblos y lugares del interior de la península. Las americanas, mucho más numerosas, están dispersas por varios archivos españoles y americanos.

La originalidad de esta fuente, sin parangón coetáneo, descansa en la modernidad de su concepción y en la riqueza, vivacidad y sugerencia de la mayoría de las respuestas. Intentar conocer el territorio, sus pueblos,

Fernando Arroyo Ilera: Departamento de Geografía de la Universidad Autónoma de Madrid.

Estudios Geográficos

Tomo LIX, n. ${ }^{\circ} 231$, abril-junio 
gentes, economía, constumbres, etc. mediante este procedimiento, directo y homogéneo a la vez, y hacerlo en una época en la que la descripción geográfica se movía entre la crónica, la genealogía o la narración arqueológica fue sin duda un arriesgado ejercicio de modernidad. Por orden de la Corona se elaboraron unos cuestionarios en los que, de forma sistemática, se contenía todo un repertorio de temas que, aún hoy, constituyen, unos más que otros, un modelo de encuesta para el conocimiento de un espacio y de la sociedad que lo habita. El resultado fueron unas completas descripciones de cada lugar, según los criterios corográficos al uso, de ahí el sobrenombre de topográficas con el que generalmente se las conoce desde que Fermín Caballero, su descubridor de hecho tras las menciones que de ellas hicieron Clemencín y Lafuente, las designó así en un estudio pionero de 1866, y que constituyó su discurso de ingreso en la Real Academia de la Historia.

Pero a medida que se las estudia con más cuidado, se pone de manifiesto que las Relaciones superan con creces lo estrictamente topográfico y corográfico para constituir un completo estudio geográfico. Por eso Jimenez de la Espada (1881) las llamó Relaciones Geográficas. Pero incluso esa denominación se queda corta, pues se trata de auténticas descripciones histórico-geográficas, como precisaron Miguélez (1915), Ortega Rubio (1918) y Reparaz (1943), o mejor aun histórico-geográfico-estadísticas, que es la triple denominación que les dio Viñas Mey (1951).

Lo más importante desde nuestra perspectiva es que ese método de actuar constituye un precedente de las investigaciones y averiguaciones catastrales que se emprendieron a partir del siglo xviI, y muy especialmente de las llamadas Respuestas Generales del Catastro de Ensenada, hasta el punto de que algunos autores han creído ver también una finalidad fiscal en este ingente esfuerzo por el conocimiento geográfico de España realizado en el reinado del Rey Prudente (Estapé, 1952: I, 68). Seguramente no fue así, pero lo que resulta evidente es que esta recopilación sistemática de datos estadísticos, geográficos e históricos como base para una descripción geográfica de España puede ser considerada, al menos, como una importante documentación paracatastral, y bajo esta perspectiva la vamos a considerar aquí.

Además, el proceso de recogida y realización de las Relaciones coincide en el tiempo con otros dos grandes proyectos de la corte escurialense: el levantamiento de un mapa de España según modernas téc- 
nicas cartográficas, atribuido con casi total seguridad a Pedro Esquivel y también conservado en la Biblioteca de El Escorial, y la realización de numerosas vistas de ciudades de marcado carácter topográfico e inestimable precisión paisajística, debidas a la genial mano del pintor holandés Anton van den Wyngaerde. Fue Sánchez Cantón quien, en un trabajo de 1914 sobre los pintores de cámara del siglo XVI, apuntó la idea de que las tres empresas - las tres por añadidura inacabadas- respondían a un mismo designio para completar el conocimiento de España desde esa triple perspectiva: la descripción, la medición y la representación pictórica. Se basaba en la indudable complementariedad funcional de los tres proyectos y en la concurrencia temporal de los mismos. De ser cierta esta hipótesis, Felipe II debería pasar a la historia no sólo como el discutido monarca más poderoso de su tiempo, sino también como uno de los más grandes geógrafos de su época, con el aliciente en nuestro caso de constituir un excelente antecedente de las modernas concep- • ciones catastrales, que no sólo buscan la recopilación estadística sino también la medición topográfica y el levantamiento cartográfico (Muro, Nadal y Urteaga, 1996). Pero la idea no pasa de ser una sugerente hipótesis de muy difícil confirmación. A pesar de la indudable preocupación por el conocimiento del espacio que caracterizó a la corte del Escorial en todo momento, es dudoso que se tuviera una noción tan completa de lo que debe ser el estudio del territorio, de la necesaria confluencia de métodos para lograr su conocimiento y de la complementariedad de técnicas descriptivas, cartográficas y fisionómicas, para que se llegara a concebir un proyecto común en este triple sentido, para lo que habría que esperarse todavía más de dos siglos. Que los tres proyectos contribuyeran a un mismo fin y se complementaran en la práctica, no quiere decir que respondieran a un solo programa previamente planificado. Además, tampoco hacía falta que fuera así. Sólo una feliz casualidad fue, sin duda, razón suficiente para la coincidencia, que todavía cuatro siglos más tarde sigue suscitando admiración e interés.

\section{Antecedentes y objetivos de las Relaciones}

La idea de esta recopilación para facilitar el conocimiento del territorio y el método de indagación directa utilizado para ello se va confi- 
gurando a lo largo del siglo xvI, recogiendo opiniones y peticiones de diversa índole. A la vez, según progresaba el descubrimiento y conquista de las tierras americanas, resultaba más necesario establecer un sistema análogo que facilitase su conocimiento y organización. Es decir, las Relaciones, en su doble vertiente - peninsular y americana- y tal como han llegado hasta nosotros, resultan de la convergencia de distintas soluciones que se dan a diferentes necesidades y que van confluyendo en un proceso común. Por eso, podemos encontrar diversos antecedentes de esta importante obra de recopilación documental. En unos casos se trata de los primeros intentos de descripción de las tierras americanas, en otros de itinerarios que preludian el estudio de las tierras peninsulares. Asimismo, puede tratarse de realizaciones prácticas, como las citadas, o de planteamientos teóricos sobre la conveniencia de utilizar este sistema frente a otros posibles o de las consideraciones razonadas que se apoyan en las ventajas del mismo. Las Relaciones fueron sin duda una obra original pero ampliamente meditada, en relación con un plan claramente definido e identificado con el sentir de una época.

Con el nombre genérico de «relación» se conoce un tipo de documento muy característico de los siglos XVI y XvII consistente en una narración breve y generalmente anónima sobre hechos variados: bélicos, políticos, biográficos, etc. En ocasiones se denominaban también «gacetas» y constituyen una fuente historiográfica inapreciable. La mayoría de los cronistas de la época utilizaron en alguna ocasión este tipo narrativo. El mismo Páez de Castro fue autor de varias relaciones que se conservan inéditas en El Escorial. No tiene pues nada de particular que el género se extendiera de forma natural a la narración topográfica y estadística que aquí nos ocupa. Por otro lado, la descripción territorial de lugares, villas y ciudades, con indicaciones más o menos precisas sobre accidentes o características particulares, tampoco era desconocida ni en América ni en la Península. Tal es el caso de varios códices de la Biblioteca Nacional, como el que lleva el número 7.855, una relación de numerosos pueblos de la Corona de Castilla de los siglos Xv y xvI (Blázquez, 1904). Asimismo otros precedentes de similar naturaleza pueden encontrase en los códices números 12.522 y 5.989 (Reparaz, 1943: 61), aunque este último, también estudiado por Blázquez, es de los primeros años del XVII.

Pero el antecedente más inmediato de las Relaciones peninsulares 
fue, sin duda alguna, la Cosmografía de Fernando Colón (1908-1915), para cuya realización recibió autorización y mandato regio. La obra de Colón es, pues, el primer intento serio de investigar la realidad geográfica de España realizado por iniciativa de la Corona. Pero en 1523, de forma inesperada y con carácter ejecutivo, Carlos $\mathrm{V}$ revocó su anterior autorización y prohibió la continuación de la empresa, cuando ésta estaba ya bastante avanzada, seguramente porque consideró que tal obra no debía ser realizada por un particular. En realidad, por aquellas mismas fechas, el interés por conocer y describir la Geografía de España no era sólo del Monarca. Pocos años antes, los representantes de las Comunidades, reunidos en la Junta de Avila, declaraban sus intenciones a este respecto, en caso de triunfar: «Que en cada un obispado se haga un libro en que se asienten todas las ciudades, villas y lugares, fortalezas y rentas que el rey tiene en aquel obispado; e que se asienten los vecinos que cada un lugar tiene, e los que tienen sus aldeas e quantos dellos son hidalgos e quantos pecheros e lo que renta cada un lugar» (Reparaz, 1943: 63). Más aun, a partir de entonces, junto a las peticiones de las Cortes a la Corona, entre 1523 a 1538, «para enmendar y copilar las leyes y hordenamientos y premáticas, para que se impriman en un volumen», se repite otra bien significativa: «y lo mismo las ystorias y crónicas viejas y antiguas de estos reynos [...] porque no se olviden las memorias de los grandes hechos de sus altos predecesores y de sus súbditos». Ello llevó a Morel Fatio a afirmar que «la nación se interesa y pide, por órgano de sus diputados a Cortes, que la redacción de los anales del país devenga una especie de servicio público, como el de la publicación de leyes y ordenanzas» (Morel Fatio, 1892).

Sin duda, fue en ese ambiente de interés histórico y geográfico cuando Páez de Castro redactó su Memorial de las cosas necesarias para escribir la Historia, en la que se muestra partidario de utilizar la encuesta directa como fuente de información. Junto al mismo se encontró un cuestionario de cincuenta y ocho preguntas al respecto (Miguélez, 1915), inmediato precedente de los que configuraron las Relaciones. Es fácil suponer la influencia que las ideas de Páez debieron tener sobre la Corte escurialense y sobre los cronistas y cosmógrafos de la época. Por eso, se ha considerado frecuentemente, y con cierta razón, a Páez como el enlace necesario entre los antecedentes de la primera época y la realización material de las Relaciones, que se emprende a partir de los años setenta. 
La preocupación por el conocimiento de las Indias llevaba otro camino. Desde el cuarto viaje de Colón, por lo menos, hay constancia de peticiones de la Corona a los descubridores y exploradores que partían al Nuevo Mundo para que enviaran noticias y descripciones de cuanto vieran y exploraran. En 1508 se ordenaba que el piloto mayor de la Casa de Contratación elaborara un padrón real con todas las noticias sobre las nuevas tierras recién descubiertas (Becker, 1917: 100). Más adelante, tras la creación del Consejo de Indias, empiezan a concretarse los primeros cuestionarios para homogeneizar los datos que debían recogerse. Es el caso del fechado en Zaragoza en 1533 y cuyos apartados se referían al nombre, número de españoles y de indios, distancias, relieve, minas, pesquerías de perlas, etc. (Jimenez de la Espada, 1881: 26). En otra cédula del mismo año se afirma: «vos mando que luego que ésta recibáis, hagáis hacer una muy larga relación de la grandeza de esa Provincia».

A partir de entonces, sólo cabía que el sistema fuera perfeccionándose. Las primeras relaciones de Indias propiamente dichas son de 1569. Otro segundo cuestionario se hace dos años después. Pero el impulso definitivo lo van a dar dos personajes clave de toda esta historia: Juan de Ovando y Juan López de Velasco. El primero, extremeño de nacimiento, murió en 1575. Fue visitador del Consejo de Indias en 1568, presidente de la misma institución en 1571 y ocupó la presidencia del de Hacienda en 1574, un año antes de su muerte. Es, como puede verse, el personaje clave que estuvo en los puestos esenciales en los momentos oportunos, por lo que, entre otras razones, Jiménez de la Espada le atribuye el principal papel en la idea originaria de las Relaciones. A él se deben, al menos, los primeros cuestionarios, de 1569 y 1571. Como Visitador del Consejo de Indias, se debe su reforma en 1570 y la elaboración de las ordenanzas que iban a regirlo, así como la creación de un cargo nuevo, esencial para todos estos objetivos: el cosmógrafo-cronista, que recayó en López de Velasco y entre cuyas obligaciones se contaba «haga y ordena las tablas de la cosmografía de Indias, asentando en ellas por su longitud y latitud y número de leguas, según el arte de Geografía, las provincias, mares, islas, ríos y montes y lugares que se hayan de poner en designo y pintura, según las descripciones generales y particulares que de aquellas partes se le entregaren, y las relaciones y apuntamientos que se le dieren por los escribanos de Cámara de Gobernación del dicho Consejo, conforme a lo cual y a lo que 
tenemos mandado en el título de las descripciones prosiga lo que fuere a su cargo de hacer en el libro general de las descripciones que ha de haber en el Consejo» («ordenanza 11». Cit. Jimenez de la Espada, 1881: 45). Excelente resumen, en prosa administrativa, de la preocupación política por el conocimiento del territorio y del método y medio que había de seguirse para llevarlo a cabo. De la misma forma, es posible que también deba atribuírsele, junto a Santa Cruz y a otros autores del momento, la idea del Libro de las descripciones, en el que el citado cosmógrafo-cronista debía recoger las noticias, relatos y relaciones que iba recopilando sobre las nuevas tierras.

Juan López de Velasco fue el íntimo colaborador de Ovando en el Consejo de Indias y, por ello, primer Cosmógrafo-Cronista Mayor de Indias desde 1571 como acabámos de decir. Ese mismo año comenzó a escribir una Geografía y Descripción Universal de las Indias, que terminó tres años después y dedicó a Felipe II. Otra obra suya fue la División y demarcación de las Indias. Además de esta labor erudita de extraordinario interés, López de Velasco, siguiendo la obra iniciada por Ovando, redactó un nuevo cuestionario para las Relaciones de Indias (1577), integrado por cincuenta preguntas y que, a diferencia de los dos anteriores, debía ser contestado en las mismas localidades objeto de la investigación y por personas expertas en el tema. Es decir, el mismo método que el establecido en 1574-75 para las Relaciones peninsulares. Además, López de Velasco demostró ser un experto en temas astronómicos mediante su método para la medición y predicción de eclipses, utilizado con éxito en los que se produjeron en los años 1577, 1578 y 1584 . Todas estas coincidencias han hecho suponer que fue también López de Velasco el autor material de los interrogatorios peninsulares, sensiblemente similares a los indianos, aunque sin excluir, por ello, la participación de otros personajes citados. Así parece confirmarlo una breve referencia de un documento conservado en Simancas ${ }^{1}$, que dio a conocer el propio Fermín Caballero (1866), en el que el Rey ordena «y asimismo ha de mandar escribir una carta a Bustos de Villegas para que mande enviar o entregar a Juan López de Velasco las relaciones que le hubieren enviado de las que él ha mandado hacer». Sin embargo, no puede excluirse categóricamente la participación también de Pedro Esquivel o Ambrosio Morales en el empeño filipense. Algunas de las relaciones citadas (San-

${ }^{1}$ Archivo General de Simanacas, Secc. Estado, n. ${ }^{\circ} 157$. 
ta Cruz de la Obispalia y Toledo) hacen referencia a que éstas fueron redactadas por «un cronista de Su Magestad», condición que había tenido Esquivel con Carlos V y que tuvo hasta su muerte Morales como cronista de Felipe II, pero que López de Velasco sólo podía aducir en parte, en cuanto cosmógrafo-cronista de Indias, cargo que desempeñó hasta 1591, cuando fue nombrado secretario del rey.

Es pues entre 1570 y 1580 , cuando se produce la confluencia de todas estas tendencias, tanto en las Indias como en la Península; tanto las disquisiciones de carácter teórico como las necesidades prácticas, todas ellas convergen en la obra que comentamos. La sucesión de todos estos acontecimientos y su concatenación en un mismo cuadro permite ver con mayor claridad muchas de las correlaciones citadas.

COMPARACIÓN CRONOLÓGICA Y CONCEPTUAL DE LAS RELACIONES AMERICANAS Y PENINSULARES

\begin{tabular}{l|l}
\hline \multicolumn{1}{c|}{ Relaciones de América } & \multicolumn{1}{c}{ Relaciones peninsulares } \\
\hline $\begin{array}{l}\text { Antecedentes desde 1508. } \\
\text { En 1530 primeros cuestionarios. }\end{array}$ & $\begin{array}{l}\text { Antecedentes en el siglo XV. } \\
\text { Itinerario de Fernando Colón (1517-23). } \\
\begin{array}{l}\text { 1570 Reforma Consejo Indias: Ovan- } \\
\text { do, presidente, y López de Velasco, } \\
\text { cosmógrafo. }\end{array}\end{array}$ \\
$\begin{array}{l}\text { Cuestionario de 1569: } 37 \text { preguntas. } \\
\text { Peticiones de la Junta de Avila. }\end{array}$ \\
$\begin{array}{l}\text { Cuestionario de 1571: } 200 \text { preguntas. } \\
\text { Cuestionario de 1574: } 24 \text { preguntas. } \\
\text { Cuestionario de 1575: } 59 \text { preguntas. Se } \\
\text { ordena que se conteste en cada pueblo. } \\
\begin{array}{l}\text { Cuestionario de 1577: } 50 \text { preguntas. Se } \\
\text { ordena que se conteste en cada pueblo. }\end{array}\end{array}$ \\
\hline
\end{tabular}

FuENTE: Elaboración propia.

Hay pues un cierto paralelismo, aunque no totalmente sincrónico, como ya señalara Martínez Carreras (1965: LX), entre ambos conjuntos de documentos. Es evidente la prioridad temporal de las Relaciones de Indias sobre las peninsulares, pero también lo es que las dos se influ- 
yeron mutuamente, sobre todo por lo que se refiere a las mejoras que se iban introduciendo, lo que resulta la mejor prueba de que respondían a un mismo proceso.

Pocos años después, en 1583, un memorial del propio López de Velasco dirigido al Rey cuando se temía que el proceso de las Relaciones se hubiera abandonado, parece dejar definitivamente claro la estrecha relación que las Relaciones peninsulares guardaban con las de Indias, así como que ambas eran parte de un proceso más amplio con el que el cosmógrafo se sentía plenamente identificado:

«Visto que en estos Reynos hay falta de una buena descripción [...] y que el hacerla por mano de quien personalmente vaya a describir y graduar los pueblos sería muy costoso y tardio, se tomó por medio distribuir por los pueblos las Instrucciones impresas que para esto se ordenaron $^{2}$ [...]. Anse por este medio recogido sin inconveniente, gasto o dilación ninguna, las Relaciones de los pueblos del Arzobispado de Toledo, en que Su Magestad fue servido que primero se hiciesse para ver cómo salía. Y de las Indias se han traído las de muchos pueblos, que por otro medio y sin mucha costa no fuera posible en muchos años.

Aviéndose juntado en Su Magestad el primero todos los Reynos de España, no se puede hazer en su tiempo obra más honrada [...] que una buena descripción que por pintura muestre los lugares de los pueblos y por escripto dé relación de lo que hay notable en ellos.

$Y$ ésta se puede hazer fácil y brevemente por el medio sobredicho, siendo Su Magestad servido que en Castilla se prosiga el recoger las Relaciones de los pueblos en las demás partes como se ha hecho en el Arzobispado [...]. Y que por los Consejos de Aragón y Portugal, o quien lo haya de determinar, se vea la forma que podrá haber para distribuir las Instrucciones impresas por los pueblos de aquellos Reynos y recoger las Relaciones, que cuando dellas no resulte otro effecto, solas ellas de por sí serán de grande estima y precio.»

PÉREZ PASTOR: La imprenta en España (cit. Zarco, 1927: 27).

Si interesante es este documento, escrito cuando la recogida de $R e$ laciones parecía abandonarse y provocaba la inquietud de López de Velasco, igual de interesante resulta la enigmática respuesta del Rey, dos días después: «Vea esto Herrera y dígame lo que le parecerá sobre ello».

${ }^{2}$ Nótese que estos mismos juicios, y casi con las mismas palabras, están contenidos en las cédulas reales que ordenaron la realización de las Relaciones. 


\section{Proceso y estructura de las Relaciones peninsulares}

Las Relaciones de la Península fueron realizadas entre 1574 y 1581. Las primeras fueron las del obispado de Coria, que se hicieron en 1574, contestándose un cuestionario de 24 preguntas que no ha llegado hasta nosotros, aunque es posible reconstruirlo gracias a las respuestas. La mayoría de las Relaciones, aproximádamente un 70\%, se realizan en 1575 y 1576 , en contestación al cuestionario del 27 de octubre de 1575 , y gran número de ellas son inmediatas a la recepción del mismo. Dicho cuestionario constaba de 57 preguntas, más otras dos, sin numerar, añadidas por la mano de Antonio Gracián, uno de los secretarios regios. Tres años después, cuando la orden parecía olvidada, se emite otra cédula, el 7 de agosto de 1578, con un nuevo cuestionario, sustancialmente similar al anterior, pero algo resumido pues sólo constaba de 45 preguntas. Las respuestas al mismo van fechadas en los dos años siguientes a su promulgación. En total más de 700 localidades, que constituyen, como ya hemos dicho, ocho gruesos volúmenes conservados en la biblioteca de El Escorial. La mayoría de estas localidades pertenece a las actuales provincias de Toledo, Guadalajara, Madrid y Ciudad Real, aunque también hay pueblos de Cáceres, Jaén, Murcia y Albacete, y algunos pocos más de Alicante y Badajoz.

El proceso que determinó la realización de estas Relaciones puede seguirse con cierta facilidad analizando las disposiciones reales contenidas en las dos cédulas, instrucciones y memorias de dichos años, y comparándolas con el relato que cada relación en particular tiene en su preámbulo. A estos efectos, la cédula de 1575, dirigida a los gobernadores de los distintos territorios de la Corona, es sumamente significativa. El Rey, al ordenar la investigación, establece:

1. $\quad$ El objetivo: para que «se haga la dicha descripción y una historia» debido a que, hasta la fecha, se carecía de ella.

2. ${ }^{\circ}$ El procedimiento: que todos los concejos y justicias de cada jurisdicción ejecuten lo dispuesto en la memoria e instrucción, lo que permitirá hacerlo «muy cumplidamente y sin dilación», debido a que «si se hubiesen de enviar personas a traer las relaciones [...] no podría haber la brevedad con la que holgaríamos».

3. ${ }^{\circ}$ La centralización de la recepción de las respuestas en el secretario del Rey, Juan Vázquez Salazar. 
La cédula de 1578 es muy similar a ésta. La única diferencia es la referencia que se hace a la disposición de tres años antes y la insistencia «para que se prosiga y acabe con el cumplimiento que conviene, se hagan en los lugares que faltaren por hacer».

Las Instrucciones que acompañaban a ambas cédulas desarrollan las fases y condiciones del procedimiento y son un buen ejemplo del minucioso funcionamiento que carecterizó a la burocracia filipense:

1. $\quad$ Los corregidores o gobernadores, tras recibir la cédula real, tenían que hacer una lista de los lugares de su jurisdicción afectados por la orden del monarca y remitir a los respectivos concejos mandamiento propio, acompañando a la cédula, instrucción y memoria del rey.

2. ${ }^{\circ} \quad$ Cada concejo «darán cargo a dos personas o más, inteligentes y curiosas [...] que hagan la relación dellos lo más cumplida y cierta que se pueda».

3. ${ }^{\circ}$ La instrucción especificaba con detalle cómo se debía responder capítulo a capítulo, leyendo dos veces el enunciado y la respuesta, escribiendo el número de cada uno al margen, etc. «respondiendo en todo breve y claramente, afirmando por cierto lo que lo fuere y por dubdoso lo que no fuere muy averiguado» ${ }^{3}$.

4. ${ }^{\circ} \quad$ Por último, cada gobernador o corregidor remitiría las Relaciones de su jurisdicción en la forma especificada en la cédula.

Fácilmente se comprenderá la importancia del proceso desencadenado por los mandatos reales. Cada cabeza de jurisdicción se convirtió en el primer escalón del proceso, y los gobernadores respectivos en piezas clave del mismo en cuanto puentes entre la Corona y cada concejo, pues eran los primeros intérpretes de las instrucciones reales. Esta labor ha quedado reflejada en los mandamientos que dichos gobernadores envían a cada pueblo de su jurisdicción y que convirtió a muchos de ellos en auténticos coautores del proceso. Este fue el caso de Bustos de Villegas, gobernador del arzobispado de Toledo, o el de Jerónimo Briceño, que lo era en el Marquesado de Villena, o el de Rodríguez, del partido de Zorita y el del Dr. Oviedo, del de Uclés, etc. En cada jurisdicción debió hacerse una lista de los lugares a los que se enviaba el mandamiento y del

${ }^{3}$ Nótese, a rasgos generales, la similitud con el proceso seguido dos siglos después para la redacción de las Respuestas Generales del Catastro del Marqués de la Ensenada (Camarero, 1993) 
que se debían recibir las Relaciones ya acabadas. Una de éstas, por ejemplo, la del partido de la villa de Uclés, provincia de Castilla de la Ordén de Santiago, figura copiada en la relación de Buenameson (Zarco, 1927: 186) anejo al mandamiento del gobernador. Cuando en cada pueblo o villa se recibía éste, en ocasiones llevado por persona que tenía «vara alta de justicia», como en Alcocer (Zarco, 1927: 141), se reunía el concejo, «a campana tañida» dice la relación del Acebrón (Zarco, 1927: 127), que por lo general estaba integrado por los alcaldes ordinarios, un número variable de regidores y el alguacil. También podían asistir los justicias. El concejo, así constituido, recibía y acataba la disposición real, «nemine discrepanti» se precisa en el Acebrón, y procedía a designar a las personas que debían contestar las preguntas del cuestionario. En la mayoría de los casos (más del 70\%) la designación recayó en dos o tres personas. Relativamente frecuentes (un 10\%) fueron las designaciones de cuatro personas y excepcionales las de más, como en Leganiel, donde se comisionó a diez vecinos, o de menos, caso de Belmonte, cuya relación fue contestada por un solo vecino (Zarco, 1927: 178).

Éstos fueron los auténticos autores de las Relaciones. Vecinos de cada lugar, conocedores del mismo, personas de edad por lo general, sinónimo de experiencia y conocimiento en la sociedad rural de la época. Este hecho se explicita en varias ocasiones (Acebrón, Huélamo, etc.), en otras queda reflejado en los frecuentes apodos de los comisionados («el viejo»), en algún caso, como en Tarazona de la Mancha, incluso se especifica la edad: «más de setenta años» (Zarco, 1927: 507). En la mayoría de los casos labradores y campesinos, pero también hay representantes de profesiones no agrícolas, aunque integradas en la población rural, como médicos (García Muñoz, El Toboso, Daimiel, etc.), clérigos (Garci Muñoz, Enguídanos, Gabaldón, Las Mesas, Pareja, Carcelén, Yeste, etc.), inquisidores (Jumilla), también militares (Vara del Rey, las Pedroñeras, Daimiel, etc.), cronistas (Chinchilla). En Iniesta se nombra a un «licenciado». Relativamente frecuente es que los comisionados, o al menos uno de ellos, fuera algún miembro del concejo: uno de los alcaldes o algún regidor. Incluso, en el caso de Barchín del Hoyo, fue el propio concejo el que se autocomisionó para responder lo mandado por el monarca (Zarco, 1927: 165). Todos estos representantes de la sociedad de la época fueron los que, reunidos ante testigos, en presencia del escribano y suponemos con toda solemnidad, procedieron a contestar al interrogatorio de la memoria. 
La relación de Tarazona de la Mancha permite seguir el desarrollo de todo el proceso mencionado. El mandamiento del gobernador fue leído al concejo de esta villa el 19 de diciembre de 1575. Dos días después, el 21 del mismo mes, dicho concejo, reunido en pleno, designa a los dos comisionados, ambos «vecinos de esta villa, [...] personas hábiles y de setenta años arriba», para contestar al cuestionario. El día 23 de diciembre dicho nombramiento fue notificado al primer comisionado y, el día siguiente, al otro. Ambos vecinos se reúnen, por último, con el escribano el mismo día 25 de diciembre para contestar a las preguntas del interrogatorio, labor que suponemos se terminó en ese mismo día, o todo lo más el siguiente. De esta forma, en menos de una semana el proceso estaba concluido (Zarco, 1927: 507-508). En otros casos, si se requerían consultas externas que obligaban a hacer alguna interrupción, el procedimiento podía alargarse algunos días más, pero siempre fue un proceso relativamente rápido. Por eso, no es de extrañar que, cuando se producían demoras - caso de Belmonte-, los responsables trataran de exculparse como fuera. Por la misma razón, en otros casos se especifica con detalle las penas en que podían incurrir los culpables de la demora: «enviad ante mí, dentro de veinte días, para que juntas con las demás se envien ante S.M., con apercibimiento que os hago que el término pasado e no las habiendo enviado, enviaré persona a vuestra costa que os compela a las hacer, procediendo como contra inobvedientes a los mandamientos de S.M.». Clara manifestación de la resistencia o abulia con la que se realizaron las Relaciones en algunos casos y que habrá que tener en cuenta para comprender el abandono final de la empresa.

La misma relación de Tarazona, por otro lado, explicita los gastos que todo este proceso suponía y en quien recaían: «os mando que paguéis al dicho Pedro de la Torre, alguacil, los salarios del tiempo que en esto se ocupare, de la ida y de la vuelta y detenimientos, a razón de trescientos y cincuenta maravedies por día, y pagándole cada uno de vos los dichos concejos lo que por el dicho alguacil os fuera repartido, los cuales le pagad de los maravedíes aplicados a gastos de justicia», y en caso de que ello no fuera posible debían pagarse con cargo a los bienes de propios ${ }^{4}$.

${ }^{4}$ Esta es una diferencia esencial respecto al procedimiento seguido en la realización del Catastro de Ensenada, que en ningún caso repercutió los costes de su realización sobre los bienes de los pueblos correspondientes. 
En casi setecientos casos, las preguntas fueron pronta y puntualmente contestadas. En varios de ellos se aportaron datos y noticias que superaban con creces lo demandado dando lugar a esta rica documentación. En dos casos (Pastrana y el Campo de Montiel) incluso se añadió una representación cartográfica de la zona. Se trata de dos interesantes mapas, o mejor simples croquis de los lugares de los que se habían evacuado respuestas con los que se pretende completar la información pedida y que constituyen una muestra del espíritu como el que presidió la realización de las Relaciones (López Gómez, 1993)

\section{La encuesta y el contenido de los cuestionarios}

Pero la auténtica novedad de todo este proceso, la que convirtió a las Relaciones en un documento único y adelantado a su tiempo y, a la vez, la que explica su inviabilidad en el momento, estriba en esos dos aspectos ya citados: el procedimiento escogido de encuesta directa a los vecinos de cada pueblo, y el tipo de preguntas que integraban los cuestionarios correspondientes.

La primera y fundamental diferencia de las Relaciones peninsulares respecto a sus inmediatas antecesoras de las Indias fue el de encuesta directa que aquéllas tuvieron desde el principio. Las americanas anteriores a la reforma del Consejo de Indias eran unos repertorios de cuestiones que exploradores, conquistadores o colonizadores debían rellenar para dar cuenta así a la Corona de las tierras recién ocupadas. La diferencia de método respecto al procedimiento implantado en España en 1575, y luego imitado en América en las Relaciones de 1577, es evidente. Este último responde a un criterio de encuesta antropológica o sociológica que tardará muchos siglos en generalizarse en estas disciplinas. El sujeto de estas encuestas no es el observador que llega de fuera y describe lo primero que ve, sino unas personas representativas del mismo medio que quiere investigarse. Sus respuestas son mucho más ricas y cualificadas por necesidad, aunque también más sesgadas por el propio medio, lo que no es ningún inconveniente siempre que se las pondere debidamente. De ahí que, hoy día, las Relaciones constituyan una excelente fuente de información para la Geografía de la percepción o la Historia de las mentalidades, por ejemplo, pero no es arriesgado suponer que, por la misma razón, en su día no lo fueran. 
Como en toda entrevista o encuesta sociológica, también en las Relaciones hubo una relación directa entre personas, con una vía de comunicación simbólica, unos objetivos prefijados y conocidos y una asignación de roles (Fernández y Carrobles, 1983: 203). A este respecto, las Relaciones son un buen ejemplo de encuesta abierta, aunque de preguntas estructuradas que siguen un orden lógico de temas y facilitan una amplia gama de respuestas. Así, junto a datos concretos, como el nombre del pueblo, el de los pueblos vecinos, ríos, montes, etc., se pedían valoraciones, tales como distancias, rendimientos, volúmenes, etc., opiniones y conocimientos sobre «hechos señalados y cosas dignas de memoria, de bien o mal», y mejor aun, la última pregunta de ambos interrogatorios requería genéricamente sobre «todas las demás cosas notables y dignas de saberse [...] aunque no vayan apuntadas ni escritas en esta memoria». Fácilmente se comprenderá que, ante tan amplia invitación, los encuestados tendieran a responder con bastante libertad, dando lugar a una información muy variada y, en ocasiones, sugerente e ilustrativa.

Por ello, los textos resultantes reúnen las condiciones mínimas de representatividad, homogeneidad y pertinencia, que se exigen hoy día para dar una mínima fiabilidad a cualquier instrumento de este tipo (Clemente y Santalla, 1991: 39). En efecto, las Relaciones son representativas del sentir y de la actitud de la región y época en que se producen, en cuanto constituyen una muestra suficientemente amplia para recibir tal calificación. Los encuestados eran personas cualificadas, elegidas por terceros, alcaldes y regidores, expresamente para contestar a este interrogatorio. Fueron, además, personas de cada lugar a las que se suponía un alto grado de representatividad respecto a la comunidad de la que formaban parte. Las Relaciones son, asimismo, homogéneas en cuanto que las respuestas obedecen a criterios precisos de selección, como son los cuestionarios citados. Por último, como acabamos de ver, las Relaciones son, por su carácter de transcripción directa e inmediata de respuestas libres y abiertas, una fuente totalmente pertinente para el objetivo que se proponía (Berg, 1990: 5ss.), por lo menos lo son desde nuestro actual punto de vista historiográfico y científico, lo que nos permite considerar a esta fuente como un antecedente inmediato de los métodos de la moderna historia oral (Thompson, 1978: 31).

La duda es si lo fueron también para los medios y posibilidades del si- 


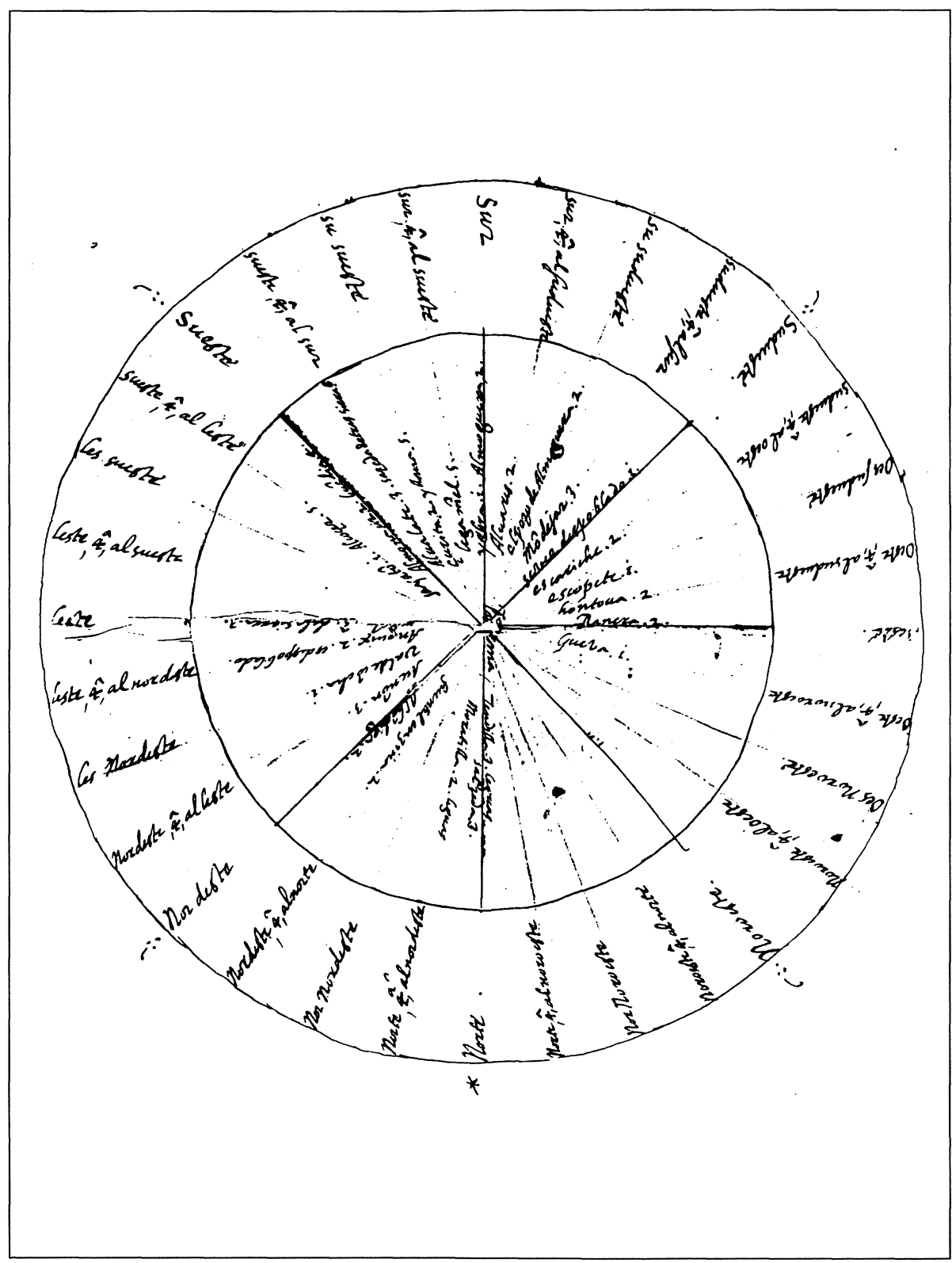

Mapa de los alrededores de Pastrana, incluido en su relación (Biblioteca de El Escorial). 


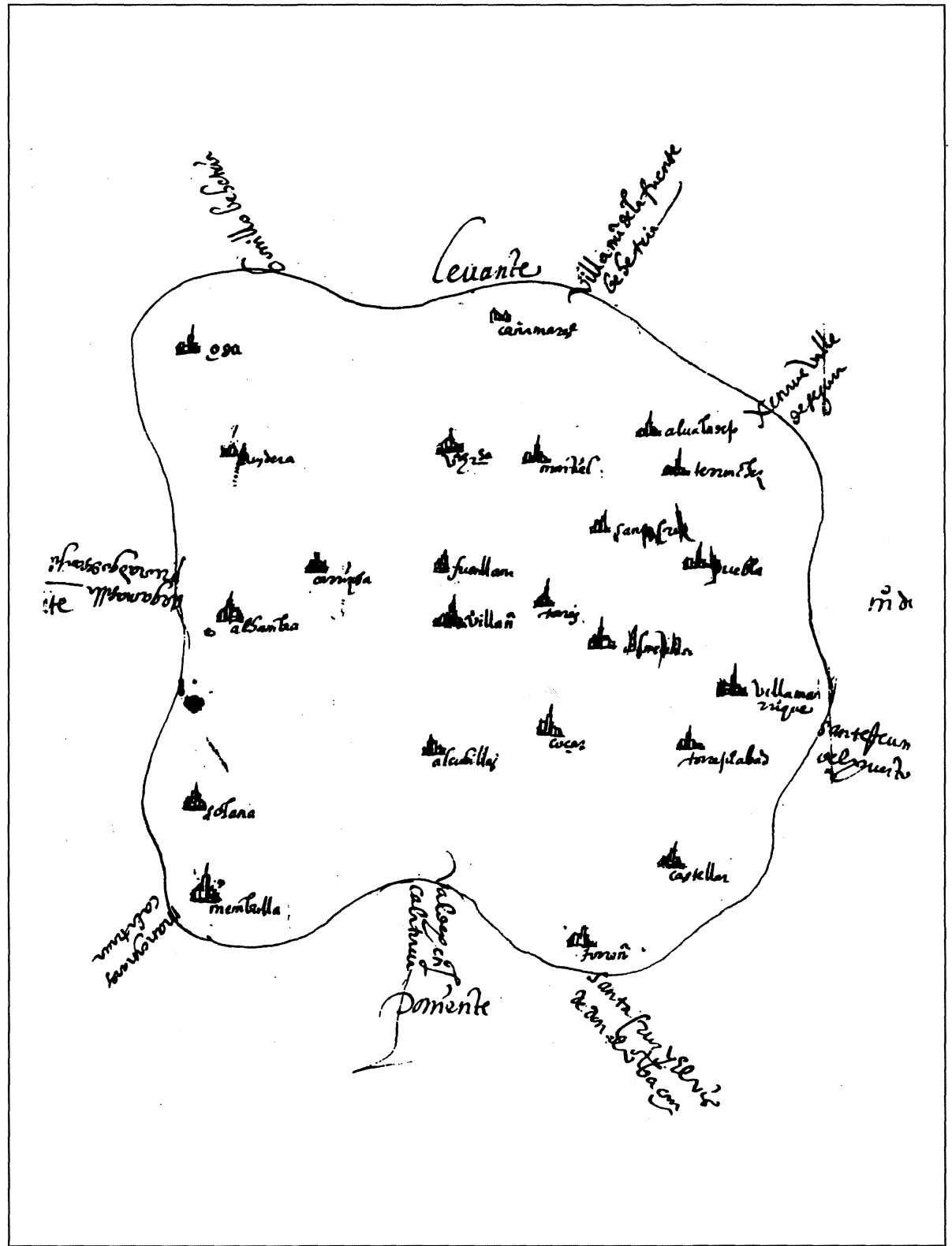

Mapa del Campo de Montiel, incluido en la relación de Villanueva de los Infantes (Biblioteca de El Escorial). 
glo Xvi. A diferencia de las Relaciones de Indias, que pretendían la recogida de información para tener un archivo de datos prácticos y aplicables a las exigencias de la administración colonial, ${ }^{5}$ las de la península exigían una reelaboración posterior. Para llegar a constituir la descripción e historia general tantas veces citadas hacía falta que alguien las utilizara y elaborara sobre ellas esa descripción e historia. Y ello no debió ser tan sencillo, aunque fuera por exceso, para los criterios y usos historiográficos de aquella época, más dados a lo político y narrativo que al análisis sociológico y antropológico de la realidad geográfica. El enfoque histórico dominante era esencialmente político y providencialista y prestaba poca atención a la vida de la gente corriente, de sus ilusiones y problemas. Sin embargo, fueron éstos los que hablaron en las Relaciones, y lo hicieron de su vida cotidiana que el cronista difícilmente iba a saber interpretar.

Además, tampoco el contenido geográfico de los interrogatorios ayudó a ello. Muchas de las preguntas parecen concebidas más en relación con el concepto y los objetivos actuales de la Geografía y de la Historia, que con lo que en el siglo Xvi se entendía por tal. Por lo general, y desde que Caballero atribuyó a Ambrosio Morales la paternidad de esta obra, se ha venido considerando a Páez de Castro como el autor moral de la idea. Así lo consideró el mismo Miguélez al publicar el cuestionario de 58 preguntas que encontró entre los papeles del cronista de Carlos V. Esta teoría podría ser cierta seguramente en lo que se refiere al método seguido en el proceso, pero no lo es respecto al contenido de los cuestionarios, notablemente diferentes como salta a primera vista. No ocurre así entre los dos cuestionarios de las Relaciones peninsulares y el de Indias de 1577, que, como ya señalara Jiménez de la Espada, concuerdan en un buen número de capítulos, al igual que se observan múltiples coincidencias en las cédulas y en las instrucciones respectivas (Jiménez de la Espada, 1881). Por el contrario, el cuestionario de Páez es un completo repertorio de los temas que en el Renacimiento interesaban a los historiadores locales. Sólo las seis primeras preguntas tienen alguna relación con temas puramente geográficos, como la situación, límites, medio físico, etc. El resto se refiere al más variado repertorio de temas jurisdiccionales, eclesiásticos, administrativos, etc., con una cla-

${ }^{5}$ Por eso las Relaciones de Indias continuaron hasta el siglo XIX, tras un corto paréntesis en la segunda mitad del siglo XviI. (Ver Solano, 1988). 
ra orientación hacia aspectos de constumbres, prácticas sociales, más propias de un estudio etnográfico que puramente geográfico o histórico. Por el contrario, los interrogatorios de 1575 y de 1578, a estos efectos muy similares, constituyen excelentes repertorios de temas geográficos e históricos, algunos de los cuales son de excelente actualidad. ${ }^{6}$ Así, por lo que se refiere al más largo y completo, el de 1575, podemos sistematizar sus 59 preguntas de la forma siguiente:

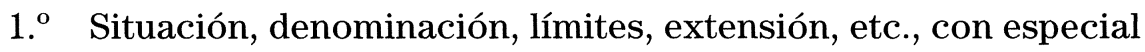
referencia a las relaciones jurisdiccionales: capítulos 1 al 16 .

2. ${ }^{\circ} \quad$ Características del medio físico y sus aprovechamientos como recurso natural: capítulos 17 a 24 .

3. ${ }^{\circ}$ Caracteres de la explotación económica: capítulos 29 a 31.

4. ${ }^{\circ}$ Hábitat, poblamiento y demografía social: capítulos 32 a 42.

$5^{\circ} \quad$ Administración, rentas y organización eclesiástica: capítulos 43 a 53 .

Los restantes capítulos se refieren a temas monográficos de especial interés, como hospitales (54), si es pueblo «pasajero» (55), despoblados (56), ferias y mercados (58), etcétera.

Excepto en algunos casos concretos, los mismos capítulos se repiten en el cuestionario de 1578, en la mayoría de los casos con la misma redacción. Sólo cabría notar alguna diferencia debida a la eliminación de algunas preguntas muy puntuales, como la relativa a las salinas, así como las que pudieran tener un cierto valor fiscal o político, como diezmos, rentas de hospitales y de caminos, voto en Cortes, alcaides de los castillos, etc. Ello debido sin duda a la necesidad de resumir el cuestionario original y también de no confundir a los destinatarios sobre las sinceras intenciones de la Corona y su propósito de utilizar los datos sólo con una finalidad «para la descripción e historia de los pueblos que es lo que en esta diligencia se pretende, sin tener fin a otra cosa, más de sólo a saber las cosas notables y señaladas de que los pueblos se pueden honrar para la historia dellos». (Instrucción de 1578. Zarco, 1927: 631).

${ }^{6}$ Véase, por ejemplo, la introducción de Rafael Sánchez Mazas en el tomo primero del Diccionario Geográfico de España. Madrid, Editorial Prensa Gráfica, 1956, págs. VILXIII. 
Las Relaciones: de materiales para una Historia inacabada a precedente de documentación paracatastral

Pero, para ese fin: la «descripción e historia de los pueblos de España», todos los temas contenidos en los cuestionarios aludidos tenían difícil aplicación. Los estudios geográficos a finales del siglo XVI giraban, en primer lugar, alrededor de la herencia ptolemaica, que en síntesis no era más que una geografía astronómica con un repertorio de topónimos localizados en el marco de coordenadas del geógrafo griego. Esa localización descansaba en unos cálculos que contenían un importante margen de error, que sólo la experiencia y cálculos de numerosos cosmógrafos permitieron corregir. Tal fue el caso de Nebrija, con su In Cosmographiae libros introductorium (1499), o mucho más importante la de Miguel Servet, cuya traducción de la Geografía de Ptolomeo (15351541), y la importante colección cartográfica que la acompañaba, contiene ya las bases de las correciones matemáticas necesarias (Bullón, 1928). Pero difícilmente esa Geografía general y astronómica podía servir de base genérica para una Descripción de España hecha con los materiales recogidos por las Relaciones. Su objetivo de generalidad se limitaba a la localización de ciertos accidentes y hechos geográficos. Todo lo más, aceptaba una sucinta descripción de los lugares como meras referencias espaciales sin ningún criterio de conexión o causalidad. Esta Cosmografía o Geografía propiamente dicha era definida por Apiano de la siguiente forma:

«¿Qué cosa es Geografía?, es una forma o figura imitación de la Tierra y sus principales partes conocidas, de las cuales la redondez de la Tierra conocida es compuesta y de las cosas más señaladas que en dichas partes se hallan [...] El fin de la Geografía y perfección della consiste en la consideración de la redondez de la Tierra.»

(Cit. Kagan, 1989: 41)

Había también otra tendencia geográfica, o mejor corográfica, como se acostumbraba a decir en la época, a la que los descubrimientos pusieron de moda, geografía descriptiva de lugares, viajes, costumbres, historias, etc. más parecida a la practicada en la antigüedad por Herodoto o Estrabón, aunque con cierta superficialidad y proclive a lo descriptivo, narrativo y banal. Este tipo de geografías, para hacer amena la lec- 
tura, alternaban la descripciones, muchas veces metafóricas e hiperbólicas, con el relato de acontecimientos, vidas de personajes, «pintura» de paisajes, etc. El mismo Apiano, y en la misma obra, definía esta otra geografía con los siguientes términos:

«Corografía es la misma cosa que topografía, la cual se puede decir traza del lugar [...] considera todas las particularidades y propiedades por minimas que sean que en los tales lugares se hallan dignas de notar: puertos, lugares, pueblos, vertientes de ríos, [...] edificios, casas, torres, murallas.»

(Cit. Kagan, 1989: 41)

En principio, éste parecía ser el enfoque más adecuado para utilizar la información recogida en las Relaciones y poder así sistematizarla en algún tipo de descripción. Pero las Relaciones contienen mucho más que ese tipo de datos que abundaban en las corografías al uso: relatan hechos, apuntan causas, establecen conexiones, contienen, en definitiva, los elementos de la percepción del medio por los individuos que lo habitan; en ocasiones, incluso, hay una auténtica «historia de vida colectiva» (Thompson, 1978). Como respuestas a una encuesta abierta, las contestaciones son muy variadas, y se hubiera requerido un principio de geografía general, del que se carecía, para homogeneizarlas.

Por lo general, se tenía a la primera Geografía, ciencia más general, como superior teórica e intelectualmente a la Corografía, pero era corriente afirmar que esta última tenía un papel fundamental para lograr una auténtica descripción geográfica general y, a la inversa, que la Corografía sin Geografía carecía de condición de ciencia (Capel, 1974: 92). Esa fue la intención de la Suma de Fernández de Enciso, de muchas de las obras de Sebastián Münster, o de la Cosmografía del mismo Apiano, pero tan sólo con un relativo éxito. Habrá que esperar, por lo menos, hasta Varenio para lograr un esquema teórico en el que ambos planteamientos, una de las disyuntivas básicas de la Geografía; empezaran a ser concordes. Pero las Relaciones se habían adelantado casi un siglo a la divulgación de la obra del gran geógrafo alemán. ${ }^{7}$ Por ello, a fines del siglo XvI el problema resultaba irresoluble.

\footnotetext{
${ }^{7}$ Varenio elaboró veintiocho factores que, según él, debía tener la Geografía Especial y que guardan gran semejanza con los temas de los interrogatorios de las Relaciones (Capel: 1974: 145).
} 
De esta forma, la Corte del Escorial se encontró con una importante colección de datos personales y vivenciales que respondían a un cuestionario muy preciso y pormenorizado de casi imposible generalización y utilización para el fin previsto. En 1583 López de Velasco hacía, como hemos visto, un último intento ante el Rey para proseguir con las Relaciones. El Monarca pidió el dictamen de Juan de Herrera. No conocemos la respuesta del famoso arquitecto, pero no debió ser muy favorable. Hay que tener presente que un año antes el mismo Herrera había conseguido del Rey la creación de una Academia para centralizar todo este tipo de trabajos, integrada por Labaña, Ondériz, Firrufino, García de Céspedes y otros cosmógrafos, aparte del mismo Herrera (Blázquez, 1904: 17). Todos ellos, excepto el arquitecto, son miembros ya de otra generación. Esta institución debió quedar encargada de la empresa, así como también de la continuidad de los trabajos de Esquivel, pero seguramente con otro enfoque. Tampoco Ambrosio de Morales parece que utilizara este filón para sus Antigüedades..., que son un poco anteriores a aquéllas. Su muerte, en 1591, coincidió con el nombramiento de Velasco como Secretario del Rey, con lo que, al abandonar éste el cargo de Cosmógrafo de Indias, quedó definitivamente apartado de la obra. Todo lo más, los datos de las Relaciones pudieron ser utilizados por Diego Pérez de Mesa, como sospechó Miguélez (1915: 57), para la redacción de la segunda parte de las Grandezas y cosas memorables de España, que en su día iniciara Pedro de Medina, pero tampoco hay absoluta seguridad en ello.

A principios del siglo xviI, poco después de que el conde de Lemus, presidente del Consejo de Indias, dictara un nuevo cuestionario de 355 capítulos para las Relaciones de Indias, ${ }^{8}$ Juan Bautista Labaña, miembro de la citada Academia que presidiera Herrera y que, como López de Velasco, fue también cosmógrafo y cronista del Rey (Blázquez, 1904: 18) reemprende las labores para levantar el mapa de España que las muertes de Esquivel y Guevara habían dejado inconcluso. Para ello, retoma el sistema de utilizar un custionario para sistematizar las averiguaciones previas a los trabajos cartográficos, pero con dos notables diferencias: el cuestionario era contestado por un experto de la propia investigación - como el propio Labaña en Aragón o Gabriel de Santans en Andalucía-

8 Según Jiménez de la Espada (1881: 74), el autor de este cuestionario fue el cosmógrafo García de Céspedes, miembro, como Labaña, de la Academia fundada por Herrera. 
y no por vecinos del lugar como se hacía en las Relaciones, y su objeto era más reducido y monográfico, similar a lo que más tarde serán los diccionarios geográficos. Por este procedimiento se generaron varios repertorios de descripciones correspondientes a los años 1610, 1623 y 1624 (Blázquez, 1904: 19), pero de estructura y funcionalidad muy diferentes a las propiamente filipenses. Al año siguiente, 1625 , se vuelve a encargar la «descripción general de España» a los cosmógrafos Pedro Teixeira, Pérez Manjón y Santa Ana y se dicta otra disposición, que en realidad no es más que un simple resumen de las de Felipe II de 1575 y 1578, en las que se ordena «me embiaréys relación particular con vuestro parecer» (Jiménez de la Espada, 1881: 282), y que no debió tener un cumplimiento muy estricto.

Es en el siglo XviII cuando tiene lugar el entronque de las Relaciones con otros grandes procesos de recogida de datos geográficos, estadísticos, históricos, etc., y especialmente con el que fue el llevado a cabo, entre 1750 y 1756 , como fase inicial del Catastro de Ensenada, consistente en un cuestionario de 40 preguntas, y que dio lugar a las denominadas Respuestas Generales (Matilla Tascón, 1946; Camarero, 1993). De finalidad prioritariamente fiscal, su información va mucho más allá y constituye sin duda la más completa información geográfica del país en el siglo XVIII. Años después, el mismo Floridablanca pretendió hacer un Diccionario Corográfico, utilizando las Respuestas Generales del Catastro de Ensenada y las Relaciones de Felipe II, y al comparar ambas fuentes afirma del Catastro «las respuestas de los pueblos no recayeron sobre preguntas tan esquisitas como las que contenía la Instrucción citada» (se refiere a la de Felipe II) (Camarero, 1989: 450), lo que evidencia la existencia de una relación genética entre ambas fuentes 0 , al menos, la idea que en el siglo xviII se tenía de que ello fuera así.

Unos años después, ya a finales del siglo, Tomás López realizó otra encuesta de 14 preguntas que dieron lugar a 20 volúmenes que constituyen el mal llamado Diccionario Geográfico de dicho autor, y cuya finalidad era, al igual que las relaciones recogidas por Labaña, servir de información previa para los trabajos cartográficos de su autor, además de acopiar noticias para el diccionario geográfico que parece pretendía realizar (López Gómez, 1996). Según el mismo cuestionario se llevó a cabo otra encuesta, por los mismos años y de similar propósito y naturaleza, en todos los pueblos del arzobispado de Toledo, que lleva el nombre de su titular en aquel entonces y promotor de la obra, el cardenal Francisco 


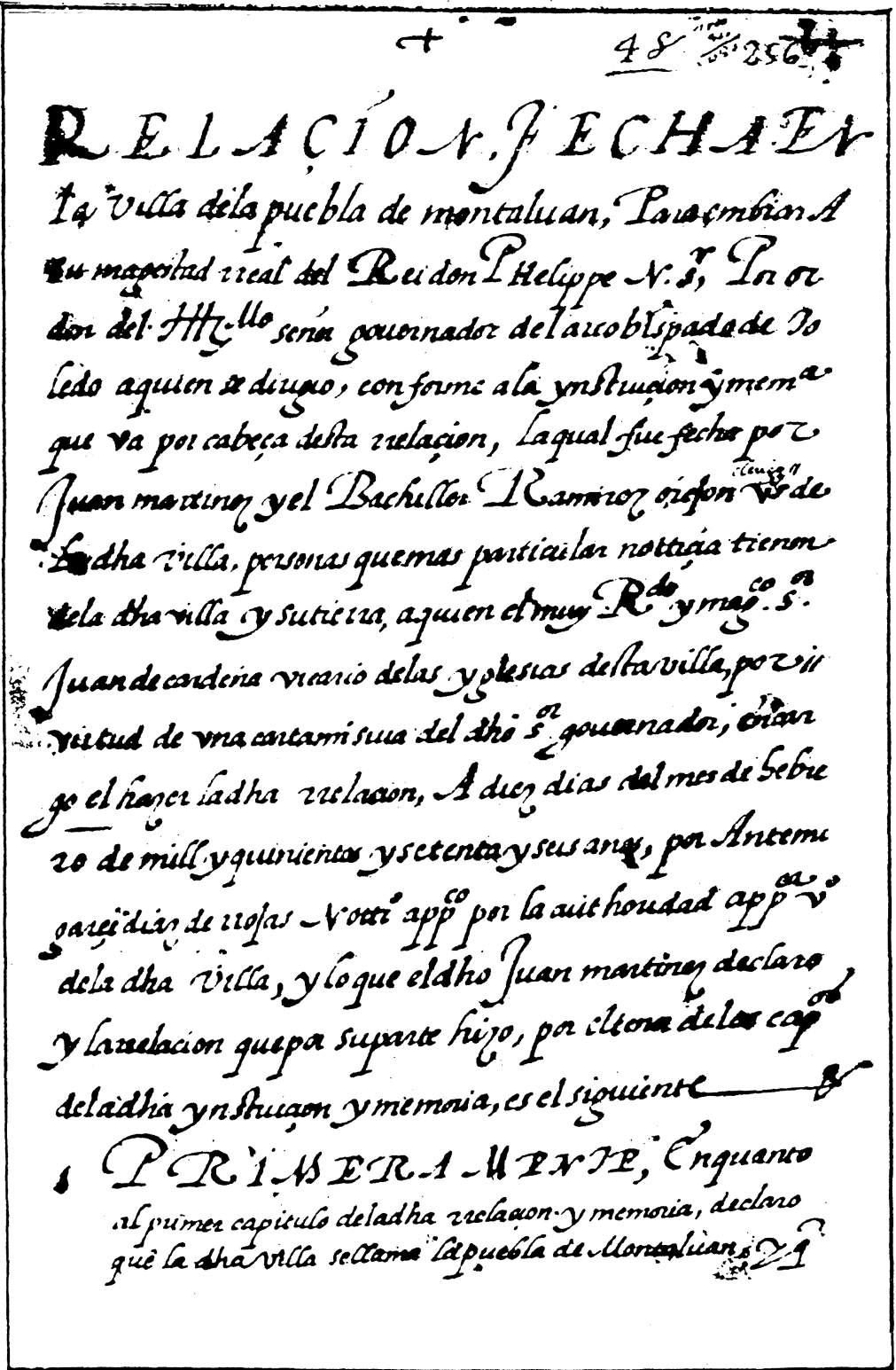

Primera página de la relación de La Puebla de Montalbán. (Biblioteca del Monasterio de El Escorial). 


\section{Puebla de MONTAlbaN $48 \%$ \% 34}

RELACION ficha en la viUla dela Puebla de Mintaban para embiar a su maj. Real del-Rev 9 . Phelippe nuestre Señor por orden del illmo sor Govemador del arzobripado de Tatedo a queven se ainaio conforme a la instruccon y me-

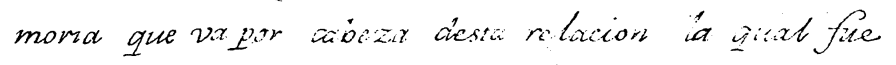
fecha por Tua it Cartinez y el bachither Tamirez Orgion: clerigo-vecinos dela dicha vilha personas que nas particular moticia tzenen de la wha vitla $y$ su tierra a quien el muy reverendo y magnifico señor Tuan de Gardeña viciorio de las yglesias desta vitha. por virtud de una carta inisiva del tho señor Gover: nador encargo el hacer la tha relacion a diez dias del mes de Zebrero de mit y quinientos y setenta y seis años por ante m Ganidiax de Rojas notario apos. tolico por la autoridad apostolica vecins de la dha villa. y to que el tho Tuan e Trartinez declaro yla velacion que por su parte hizo por el tenor de los capitiulos de, la dha instruaion $y$ memoria es et siguente, Primeramente on quanto al primer capitulode. ta.

Primera página de la copia de la relación de La Puebla de Montalbán (Biblioteca de la Real Academia de la Historia). 
Antonio de Lorenzana (Porres, Rodríguez y Sánchez, 1992). Asimismo, en 1770, el Consejo de Castilla publicó un cuestionario para recoger este mismo tipo de datos, a iniciativa de Mariano Nipho (Blázquez, 1904: 23), algunas de cuyas respuestas fueron publicadas en el Correo General de España, de los años siguientes. Similar es el Interrogatorio llevado a cabo por la Audiencia de Extremadura.

Pero, aunque todos estos trabajos tenían ya otra finalidad y carecían del sentido que había caracterizado dos siglos antes la magna empresa filipense, la idea y el recuerdo de las Relaciones no se perdió ${ }^{9}$ y los intentos por aprovecharlas y estudiarlas como fuente geohistórica fueron constantes. Así, en el siglo XviII, el cura párroco del pueblo toledano del Romeral, al contestar al interrogatorio de Lorenzana, cita unas relaciones de este pueblo que atribuye equivocadamente a tiempos de Carlos V, custodiadas, según él, «en el Archivo de Simancas, dada por Antón Pérez, escribano de este ayuntamiento, en respuesta a setenta y dos preguntas que se hicieron a los pueblos» (Porres, Rodríguez y Sánchez, 1986: 520). Se trata, naturalmente de las Relaciones de Felipe II, sólo que el cura cita erróneamente una copia incompleta, además de equivocarse en el número de preguntas y en el archivo, lo cual no obsta para demostrar que el recuerdo de las Relaciones filipenses se mantenía en la memoria colectiva de las gentes identificándose con cualquier nuevo interrogatorio que se veían obligados a contestar. Asimismo, también algunos pueblos, como Chinchilla o La Roda, que guardaban copias de las Relaciones, transcribieron algunos de sus párrafos, dos siglos después, para contestar el interrogatorio de Tomás López (Rodríguez de la Torre y Cano Valero, 1987: 187 y 268).

En 1772, las Relaciones fueron llevadas a la Real Academia de la Historia para servir de base a la redacción del Diccionario Geográfico e Histórico que iba a emprender dicha institución, otra obra lamentablemente inacabada, para lo que fueron copiadas en seis volúmenes que se conservan en el Archivo-biblioteca de esta Academia. Vueltas a El Escorial, de él volvieron a salir con la Desamortización y estuvieron custodiadas en la Biblioteca Nacional entre 1842 y 1855. Por esas fechas las Relaciones fueron objeto de una disposición extraordinaria en la historia de los archivos españoles: por una Real Orden de 1840 se dispone una

${ }^{9}$ Véase, a este respecto y en este mismo número, la noticia de López Gómez sobre la mención que hizo Townsend, poco antes de salir de España, referente a las Relaciones Topográficas. 
búsqueda exahustiva en todos ellos por si pudiera existir algún volumen más perdido de las mismas, con el resultado infructuoso que ya conocemos (López Gómez, 1990).

Ello enlaza ya con las constantes citas y estudios historiográficos sobre esta fuente. A lo largo de los últimos 170 años éstos han sido muy variados, clara manifestación del interés que siempre ha suscitado, y pueden agruparse en tres tipos: estudios sobre las Relaciones como fuente historiográfica, estudios que utilizan esta fuente para investigaciones históricas o geográficas, y transcripción y publicación de la obra original. Las primeras referencias historiográficas propiamente dichas son de principios del siglo XIX (Clemencín, 1821). Lafuente (1854) las utilizó también para su monumental Historia de España, pero fue Fermín Caballero (1866) quien las «dio a conocer» a la comunidad científica de su tiempo en un estudio a todas luces pionero (López Gómez, 1989). A partir de aquí el interés se acrecienta (Cánovas del Castillo, 1869; Fernández Duro, 1895; Blázquez, 1904; Ortega Rubio, 1918; Brantli, 1927; Sánchez Cantón, 1914; Becker, 1917, etc.). Pero las aportaciones más importantes son las realizadas por Jiménez de la Espada (1881) en su estudio sobre las Relaciones de Indias, por el padre Miguélez (1917), por Gabriel Marcel (1899), en su conocido estudio sobre los orígenes de la Carta de España y por el padre Zarco Cuevas (1927) en su transcripción de las Relaciones del Obispado de Cuenca. Otras transcripciones han sido las de la provincia de Guadalajara, de Juan Catalina García y Manuel Pérez Villamil (1903-1915); las de Viñas y Paz sobre Madrid, Toledo y Ciudad Real (1949-1971); la de Villegas y García, sobre Jaén (1976); y, más recientemente, las de Cebrián y Cano sobre el Reino de Murcia (1992), y de Alvar Ezquerra (1996) de nuevo sobre las de Madrid, aparte de transcripciones de relaciones sueltas o de unidades territoriales menores. Por último, las Relaciones han sido utilizadas como fuente de información en numerosas ocasiones, y aquí la nómina sería interminable, y lo está siendo cada vez más por investigadores de muy diversa procedencia (Salomón, 1964; Torres Balbás, 1933; Campos, 1988; Christian, 1981, etc.) y especialmente desde una perspectiva geohistórica con particular intensidad, permitiendo, por ejemplo, la reconstrucción de las comarcas castellanas del siglo xvi y el estudio de la casa rural de dicha centuria (López Gómez, 1989, 1990, 1993), de los molinos y de las actividades cinegéticas (Arroyo, 1990, 1991) y otros muchos aspectos de esa centuria. 
Como muestra de este interés, baste sólo una cita literaria de prestigio: la que, referida al crecimiento de la población de Infantes, hizo Azorín a principios del presente siglo, en una de sus obras más representativas: «Nunca fue menor - dicen las Relaciones Topográficas inéditas ordenadas por Felipe II-; nunca fue menor, siempre ha ido en aumento y va creciendo». ${ }^{10}$ Lo mismo cabría decir, por nuestra parte, respecto a la creciente atención por esta monumental obra de nuestro $\mathrm{Si}$ glo de Oro.

\section{BIBLIOGRAFIA}

Aguado Bleye, P. (1954): Manual de Historia de España, Tomo II. Reyes Católicos. Casa de Austria. Madrid, Espasa Calpe, 1.200 págs.

Alvar Ezquerra, A. (1993): Relaciones Topográficas de Felipe II. Madrid. Madrid, Comunidad de Madrid y Consejo Superior de Investigaciones Científicas. 2 tomos: I. Estudio Introductorio, 198 págs. II. Transcripción (2 vols.) 992 págs.

ARroyo IleRA, F. (1989): «El factor geográfico y el problema de España». En Estudios Geográficos, 195 , págs. 333-348.

- (1990): «Los molinos del Tajo en el siglo XVI, según las Relaciones Topográficas de Felipe II». En Estudios Geográficos, 199-200, págs. 259-272.

- (1991): «Caza y fauna en Castilla la Nueva en el siglo XVI, según las Relaciones Topográficas de Felipe II». En Actas del VI Coloquio de Geografía Rural. Madrid, Asociación de Geógrafos Españoles y Universidad Autónoma de Madrid, págs. 183-196.

BECKER, J. (1917): Los estudios geográficos en España. Madrid, Real Sociedad Geográfica, 366 págs.

BERG, M. (1990): «Algunos aspectos de la entrevista como método de produción de conocimientos». En Historia y Fuente oral, 4, págs. 5-10.

Blázquez y Delgado Aguilera, A. (1904): «El itinerario de D. Fernando Colón y las Relaciones Topográficas», Boletín de la Real Sociedad Geográfica, XLVI, págs. 83-105.

BratuI, C. (1909): Felipe II rey de España. Estudio sobre su vida y su carácter. Tradución española. Madrid, Bruno del Amo, 1927, 270 págs.

Bullón, E. (1928): Miguel Servet y la Geografía del Renacimiento. Discurso leido ante la Real Academia de la Historia en la recepción del Excmo. Sr. D... Tercera Edición. Madrid, Instituto Juan Sebastián Elcano, CSIC, 1945, 224 págs.

CABAllero, F. (1866): Discursos leidos ante la Real Academia de la Historia en la recepción pública del Excmo. Sr. D... Madrid, Imprenta de sordomudos y de ciegos, 84 págs.

CAMARERo Bullón, C. (1989): Burgos y el Catastro de Ensenada. Burgos, Caja de Ahorros Municipal, 528 págs.

- (1993): El debate de la Única Contribución. Col. «Alcabala del Viento», serie alfabética, Libro D. Madrid, Centro de Gestión Catastral y Cooperación Tributaria, Tabapress, 224 págs.

10 Martínez Ruiz, J. «AZORIN» (1903): «Antonio Azorín». En Obras Selectas. Madrid, Biblioteca Nueva, pág. 279. 
Campos y Fernández de Sevilla, F. J. (1988): «Las Relaciones Topográficas de Felipe II: claves para un estudio de la mentalidad castellano-manchega a fines del siglo XVI». En $A c$ tas del I Congreso de Historia de Castilla La Mancha. Tomo I, págs. 217-224.

— (1993): «Las Relaciones Topográficas de Felipe II: unas fuentes históricas monumentales sobre Castilla la Nueva en el s. XVI. En La Ciencia en el Monasterio de El Escorial. San Lorenzo de El Escorial.

Cánovas del Castillo, A. (1869): De la Casa de Austria. Bosquejo histórico. Madrid, Imprenta Universal Económica, 142 págs, $2 .^{a}$ edición, Madrid, Imprenta V. Suarez, 1911, 442 págs.

CAPEL SÁEZ, H. (1974): «Las personalidad geográfica de Varenio». En VARENIO: Geografía General. Barcelona, Ediciones de la Universidad de Barcelona, págs. 11-84.

Cebrián Abellán, A. y CANo VAlero, J. (1992): Relaciones Topográfícas de los pueblos del Reino de Murcia. Murcia, Ed. Universidad, 474 págs.

Clemencín, D. (1821): «Elogio de Isabel la Católica». En Memorias de la Real Academia de la Historia, VI, págs. 1-662 (Acto celebrado en 1807).

Clemente, M. y Santalla, Z. (1991): Documento persuasivo. Bilbao, Deusto, 236 págs.

Colón, F. (1904-1906): «Descripción y Cosmografía de España». Boletín de la Real Sociedad Geográfica, XLVI-XLVIII, Edición aparte en tres volúmenes, 1908-1915. Edición facsímil de ésta, Sevilla, Padilla, 1988.

CHRISTIAN, W. (1981): Local religion in sixteenth-century. Princeton.

DAINVIlle, F. de (1969): La Geographie des Humanistes. Ginebra, Slatkine, 348 págs.

FERnÁNDEZ BAllesteros, R. y CARROBles, J.A.I. (1985): Evaluación conductual. Madrid, Pirámide, $784 \mathrm{pp}$.

FERNÁNDEZ DURO, C. (1895): «Geografía y descripción universal de las Indias, recopilada por Juan López de Velasco». En Boletín Real Academia de la Historia, XXVI, págs. 401-408.

GARCÍA DE CESPEDES, A. (1606): Libro de instrumentos nuevos de Geometría, muy necesarios para medir distancias y alturas... Madrid, Juan de la Cuesta.

García y López, J. C. y Pérez VILLAMIL, M. (1903-1915): Relaciones Topográfícas de España. Provincia de Guadalajara. 6 tomos: 440 págs. 500 págs. 496 págs. 336 págs. 372 págs. y 453 págs. Memorial Histórico Español. Madrid, Boletín de la Real Academia de la Historia, Tomos XLI a XLVI.

Haverkamp-Begemann, E. (1989): «Las vistas de España de Anton van den Wyngaerde». En Ciudades del Siglo de Oro. Madrid, El Viso, págs. 54-67.

JIMÉNEZ DE LA ESPADA, M. (1881-1887): Relaciones geográficas de Indias. Madrid, Ministerio de Fomento, 4 volúmenes. 2. a, edición: Madrid, Biblioteca de Autores Españoles, Ed. Atlas, 1965, 3 volúmenes.

Kagan, R. (1989): «Felipe II y los geógrafos». En Ciudades del Siglo de Oro. Madrid, El Viso, págs. 40-53.

Lafuente, M. (1854): Historia General de España. Tomo XIV. Madrid, Tipografía Mellado, 508 págs.

LóPEz Gómez, A. (1996): «El método cartográfico de Tomás López. El interrogatorio y los mapas de España». En Estudios Geográficos, 225, págs. 667-710.

López Gómez, A. y ARRoyo IlerA, F. (1994): «Las salinas interiores y el abastecimiento de sal en las tierras madrileñas a finales del siglo XVI». En Boletín de la Real Academia de la Historia, CXCI. III, págs. 413-435.

LÓPEz Gómez, Julia y Antonio (1989): «Fermín Caballero y las Relaciones Topográficas de Felipe II. Un estudio pionero». En Arbor, 526, págs. 33-49.

- (1989): «Las comarcas de Ciudad Real según las Relaciones Topográficas de Felipe II». En Estudios Geográficos, 194, págs. 65-90.

- (1990): «Cien años de estudios de las Relaciones Topográficas de Felipe II». En $A r$ bor, 538, págs. 33-72. 
López Gómez, Julia y Antonio (1993): «Dos interesantes mapas en las Relaciones Topográficas de Felipe II: El Campo de Montiel (Ciudad Real) y alrededores de Pastrana (Guadalajara)». En Boletín de la Real Academia de la Historia, CXC, págs. 173-206.

LÓPEZ PiÑERo, J. M. ${ }^{a}$ (1979): Ciencia y Técnica en la sociedad española de lo siglos XVI $y$ XVII. Barcelona, Labor, 512 págs.

Martínez CARreras, U. (1965): «Estudio preliminar». En JimÉnez DE LA EsPADA, M. Relaciones geográficas de Indias. 2. ${ }^{\mathrm{a}}$ ed. Biblioteca de Autores Españoles. Madrid. Ed. Atlas, págs. XLIII-LXVI.

MARCEL, G. (1899): «Les origenes de la carte d'Espagne». En Revue Hispanique. VI. págs. 163-193. Trad. española en Estudios Geográficos, 43 (1951), págs. 317-337.

Matilla TAscón, A. (1946): La Unica Contribución y el Catastro de la Ensenada. Madrid, Ministerio de Hacienda, 602 págs.

Melón y Ruiz de la GoRdeJUElA, A. (1950): «La geografía de Martín Fernández de Enciso». En Estudios Geográficos, 38, págs. 29-43.

Miguélez, M. F. (1915): «Las Relaciones histórico-geográficas de los pueblos de España hechas por orden de Felipe II». En La Ciudad de Dios, XCIX (hay tirada aparte)

MoRAles, Ambrosio de (1575): Antigüedades de las ciudades de España. Alcalá de Henares, Ed. facsímil librería París-Valencia, Valencia, 1996.

Morel Fatio, A. (1892): Bibliothèque Nationale. Departément des Manuscrits. Catalogue des Manuscrits espagnols et des Manuscrits portugais. París.

Ortega Rubio, J. (1918): Relaciones topográficas de los pueblos de España. Madrid, Soc. Española de Artes Gráficas, 710 págs.

Porres de Mateo, J., Rodríguez de García, H. y SÁnchez GonzÁlez, R. (1986): Descripciones del Cardenal Lorenzana. Toledo, Instituto provincial de investigaciones y estudios toledanos, 712 págs.

Reglá Campistol, J. (1963): «Edad Moderna». En Ubieto, A.; Reglá, J.; Jover, J. M. a y Seco, C.: Introducción a la Historia de España. Barcelona, Teide, págs. 265-506.

Relaciones Geográfias del siglo XVI. México, Universidad Nacional Autónoma de México, Instituto de Investigaciones Antropológicas. Serie Etnohistoria, 8 vols.

REPARAZ, G. de. (1943): «Historia de la Geografía de España». En GAVIRA, J. dir.: España. La Tierra. El Hombre. El Arte. Barcelona, Alberto Martín, 588 págs.

RODRÍGUEZ DE LA TORRE, F. y CANO VALERO, J. (1987): Relaciones geográfíco-históricas de Albacete (1786-1789), de Tomás López. Albacete, Caja de Ahorros.

ROSSELló VERGER, V. (1990): «Introducció: Unes imatges quasi desconegudes». En Les vistes valencianes d'Anthonie van den Wijngaerde. Valencia, Generalitat Valenciana, págs. 13-42.

SALOMÓn, N. (1964): La campagne de Nouvelle Castille à la fin du XVI eme siecle d'apres les "Relaciones Topográficas». París, CNRS, Traducción española: La vida rural castellana en tiempos de Felipe II. Barcelona, Ariel, 2. ${ }^{a}$ Ed., 1982, 428 págs.

SÁnchez CANTÓN, F. J. (1914): «Los pintores de Cámara de los Reyes de España (Apuntes históricos)». En Boletín de la Sociedad Española de Excursiones, págs. 133-160.

SANZ GARCíA, J. M. ${ }^{a}$ (1989): «La Imago Hispaniae. Una muestra de la cartografía del siglo XVI». En Topografía y Cartografía, 35, págs. 5-19.

Solano, F. de (1988): Cuestionarios para la formación de las Relaciones Geográficas de Indias. Siglos XVI-XIX. Madrid, Centro de Estudios Históricos, CSIC, 234 págs.

Thompson, P. (1978): The voice of the past. Oxford University Press. Trad. española, Valencia, Edicions Alfons el Magnànim, 342 págs.

VÁzquez MAure, F. (1974): «Cartografía española del siglo XVI». En VII Conferencia internacional de Cartografía. Trad. en Boletín de la Real Sociedad Geográfíca, CXVIII, 1982, págs. 141-149.

- (1975): «El plano de Toledo del Greco y su posible origen». En Kartografisch Tijdschrift. Trad. Boletín de la Real Sociedad Geográfica, CXVIII, 1982, págs. 151-155. 
VÁZQUez MAURe, F. (1981): «Análisis y evaluación del Atlas del Escorial». En IX Conferencia Internacional de Historia de la Cartografía. Pisa-Florencia-Roma. Trad. Boletín de la Real Sociedad Geográfica, CXVIII, 1982, págs. 203-214.

Villegas Díaz, L. R. y García SERRANo, R. (1976): «Relaciones de los pueblos de Jaén ordenadas por Felipe II». En Boletín del Instituto de Estudios Giennenses, 88-89, págs. 9-302.

ViÑaS MeY, C. (1951): «Las Relaciones de Felipe II y su publicación». En Estudios Geográficos, 42, págs. 131-136.

VIÑAS MEY, C. y PAZ, R. (1949-1971): Relaciones de los pueblos de España ordenadas por Felipe II. Madrid, Institutos Balmes de Sociología y Juan Sebastián Elcano de Geografía, CSIC, 5 vols. Provincia de Madrid (1949), 784 págs. Reino de Toledo, I (1951), 576 págs. II (1963), 480 págs. III (1963), 502 págs. Ciudad Real (1971), 618 págs.

Zarco Cuevas, J. (1927): Relación de los pueblos del obispado de Cuenca. Nueva edición preparada por D. Pérez. Cuenca, Diputación Provincial, 1983, 685 págs.

RESUMEN: Las relaciones geográficas y el conocimiento del territorio en tiempos de Felipe II. Las Relaciones Topográficas mandadas realizar en el reinado de Felipe II constituyen una fuente de primera magnitud para el conocimiento del territorio. Se trata de las respuestas dadas por personas de más de setecientos pueblos de la Corona de Castilla a un interrogatorio preparado por cronistas, cosmógrafos y funcionarios de la Corte de El Escorial. Se llevaron a cabo tanto en la Península como en América. En este trabajo se estudian sus orígenes, estructura, posibilidades y, sobre todo, su influencia sobre otras fuentes posteriores que, además del conocimiento del territorio, tenían ya una finalidad catastral.

Palabras ClAVE: Fuentes geohistóricas. Interrogatorio. Catastro. Averiguaciones. Felipe II.

RÉSUMÉ: Les relations geographiques et le connaissance du territoire du temps de Felipe II. Les Relations Topographiques mander faire sous le règne de Felipe II constituent une source d'une énorme importance pour la connaissance du territoire. Il sagit des réponses données par plus de six cents personnes des bourgs et villages de la Couronne de Castille suite à l'interrogatoire établi par les chroniqueurs, cosmographes et fonctionnaires de la Cour de l'Escorial et qui furent relevées à la Péninsule comme en Amérique.

Nous étudions dans le présent travail ses origines, sa structure, ses posibilités et, principalement, son influence sur d'autres sources postérieures qui ajoutaient déjà au premier but, la connaissance du territoire, une finalité cadastrale.

MOTS CLÉS: Sources geohistoriques. Interrogatoire. Cadastre. Renseignements. Felipe II.

ABSTRACT: The geographical records and territory awareness in time of Philip II. The Relaciones Topográficas that were compiled during the reign of Philip II are a primary source of territory awareness. This compilation of data is made up of the answers to a survey designed by Court choniclers, cosmographers and civil servants; answers given by people from over hundred villages belonging to the Crown of Castille. These surveys were carried out both in mainland Spain and in America. 
The author of this paper studies the survey origins, its structure, possibilities and, most importantly, its influence on other secondary sources which were already used as censuses apart from including knowledge of the territory.

KEY WORDS: Geographical and historical sources. Survey. Census. Conclusions. Philip II. 